\title{
Revistando possibilidades epistemológicas em contabilidade gerencial: em busca de contribuições de abordagens interpretativas e críticas no Brasil
}

Revisiting epistemological possibilities in management accounting: in search of contributions from interpretive and critical approaches in Brazil

Posibilidades epistemológicas en contabilidad de gestión: en la búsqueda de contribuciones con enfoques interpretativos y críticos en Brasil

\section{Rosenery Loureiro Lourenço}

Doutoranda em Ciências Contábeis pela Universidade Federal do Rio de Janeiro

Professora do Curso de Ciências Contábeis da Universidade Estadual de Mato Grosso do sul Endereço: Rua Itiberé Vieira S/N, Resid. Júlia Olinto Cardinal

CEP: 79.900-000 - Ponta Porã/MS - Brasil

E-mail: roseneryll@gmail.com

Telefone: + 55 (67) 3926-6333

\section{Fernanda Filgueiras Sauerbronn}

Doutora em Administração pela EBAPE-FGV

Professora do Doutorado em Ciências Contábeis da Universidade Federal do Rio de Janeiro

Endereço: Avenida Pasteur, n॰250 sala 250, Urca

CEP: 22.290-240 - Rio de Janeiro/RJ - Brasil

E-mail: fernanda.sauerbronn@facc.ufrj.br

Telefone: + 55 (21) 3938-5262

Artigo recebido em 28/09/2015. Revisado por pares em 18/03/2016. Reformulado em 13/05/2016. Recomendado para publicação em 21/05/2016 por Sandra Rolim Ensslin (Editora Científica). Publicado em 14/06/2016. 


\title{
Resumo
}

O presente artigo reconhece que a contabilidade retrata uma parte da realidade, e nesse sentido, as pesquisas contêm visões de mundo que evidenciam o conhecimento como uma razão entre sujeito e objeto. O conhecimento científico em contabilidade gerencial, portanto, ocorre a partir da descoberta de pesquisadores que conduzem suas pesquisas com base em pressupostos ontológicos, epistemológicos e metodológicos associados a determinadas abordagens. Este artigo revisita diferentes possibilidades epistemológicas em contabilidade gerencial e apresenta reflexões sobre a contribuição destas abordagens para a pesquisa, destacando pressupostos, possibilidades e limitações de abordagens dominantes e alternativas. As autoras desenvolvem um argumento acerca dos potenciais advindos de maior engajamento com abordagens interpretativas e críticas, que lancem novas luzes sobre os fenômenos contábeis. Para tal, é promovido um diálogo com diversos autores, de forma a apontar a possibilidade de pluralismo e coexistência de conhecimentos de naturezas diversas em contabilidade gerencial no Brasil.

Palavras-chave: Epistemologia. Contabilidade gerencial. Abordagem interpretativa e crítica.

\begin{abstract}
This article recognizes that accounting reflects a part of reality, and in this sense, the researches contain worldviews that show knowledge as a ratio between subject and object. Scientific knowledge in management accounting, therefore, occurs from the discovery of researchers that conduct their research based on ontological, epistemological and methodological assumptions associated to certain approaches. This article revisits different epistemological possibilities in management accounting and presents reflections on the contribution of these approaches to research, highlighting assumptions, possibilities and limitations of mainstream and alternative approaches. The authors develop an argument on the potential from greater engagement with interpretive and critical approaches that may shed new light on accounting phenomena. In this sense, the authors promote a dialogue with alternative literature, in order to point out the possibility of pluralism and coexistence of knowledge of different natures in management accounting in Brazil.
\end{abstract}

Keywords: Epistemology. Management accounting. Interpretive and critical approaches.

\section{Resumen}

Este artículo reconoce que la contabilidad retrata una parte de la realidad, y en este sentido, las encuestas contienen visiones del mundo que muestran el conocimiento como una relación entre el sujeto y el objeto. El conocimiento científico en la gestión de la contabilidad, de este modo, se produce desde el descubrimiento de los investigadores que llevan a cabo sus investigaciones sobre la base de supuestos ontológicos, epistemológicos y metodológicos asociados con ciertos enfoques. En este artículo se vuelve a visitar diferentes posibilidades epistemológicas en la contabilidad de gestión, y presenta reflexiones sobre la contribución de estos enfoques a la investigación, destacando las hipótesis, posibilidades y limitaciones de la corriente principal y enfoques alternativos. Las autoras desarrollan una discusión sobre el potencial que surge de un mayor compromiso con los enfoques interpretativos y críticos que arrojan nueva luz sobre los fenómenos de contabilidad. Para ello, se promueve diálogo con varios autores, con el fin de señalar la posibilidad del pluralismo y la convivencia del conocimiento de diversos tipos en la contabilidad de gestión en Brasil.

Palabras clave: Epistemología. Contabilidad de gestión. Los enfoques interpretativo y crítico.

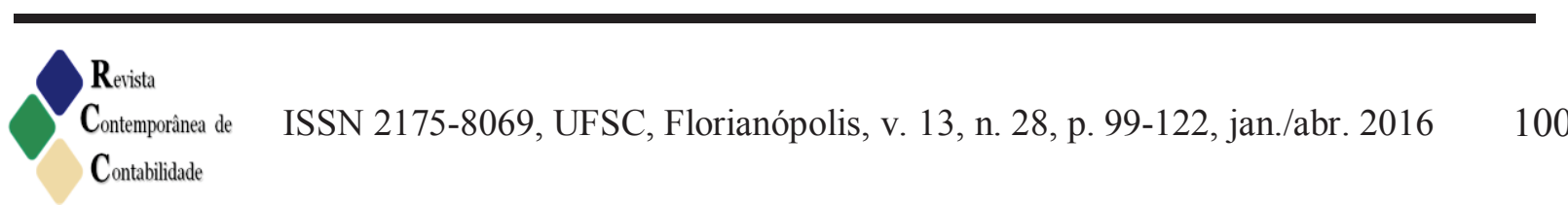




\section{Introdução}

Em um contexto de crescente interesse pela internacionalização da pesquisa contábil no Brasil, as autoras do presente ensaio consideram adequado o momento para que se questione quanto ao(s) caminho(s) a seguir na busca por essa internacionalização. Seguir a abordagem dominante no contexto internacional, particularmente norte-americano? Ou identificar diferentes caminhos, já consolidados na literatura internacional, embora não tão dominantes, para que possamos alcançar pluralismo, coexistência de perspectivas e a geração de conhecimentos outros?

Tal questionamento faz sentido ao reconhecemos que a pesquisa dominante em ciências contábeis, em geral, sustenta-se na construção de um corpo de conhecimento científico a partir da resolução de problemas, e da investigação de relacionamentos entre variáveis e de medidas objetivas (SMITH, 2011). Essa postura ontológica e epistemológica tem sido atacada, por que o ato de observar sofre influência dos motivos e preferências do observador, bem como pelo reconhecimento de que a contabilidade ajuda a criar os fatos que reporta e distorce a prática sistematicamente (HOPWOOD, 1987). Preocupações de pesquisadores como Hopwood e outros autores têm permitido, ao longo das últimas décadas, o desenvolvimento de novas abordagens para a pesquisa contábil no contexto euroamericano, dentre as quais se destacam aquelas associadas às perspectivas interpretativas ou críticas (RYAN et al., 2002).

Entretanto, apesar do desenvolvimento e do reconhecimento alcançado por essas perspectivas, Baker e Bettner (1997) questionam os motivos pelos quais a pesquisa interpretativa e crítica não estejam adequadamente representadas nos principais periódicos internacionais de pesquisa em contabilidade. Os autores apontam diversas restrições enfrentadas pelos pesquisadores norte-americanos, que tentam desenvolver conhecimentos de outra natureza, dentre elas o fato de os programas doutorais e as políticas editoriais dos principais periódicos acadêmicos serem frequentemente liderados por pesquisadores que seguem a abordagem dominante (ou mainstream), materializando-se em falta de treino, falta de interesse e falta de incentivo.

Por um lado, a existência de tais restrições no contexto norte-americano, apontada por Baker e Bettner (1997), suscita reflexões quanto às reais possibilidades de desenvolvimento, no Brasil, de perspectivas interpretativas e críticas. Consideramos que a pesquisa em contabilidade gerencial no Brasil ainda é recente, quando comparada ao contexto USA e UK, e as revistas especializadas em abordagens interpretativas e críticas são inexistentes. Por outro lado, são também inexistentes os estudos nacionais que apontem restrições diretas para o desenvolvimento de pesquisas interpretativas e críticas no Brasil. Essa constatação é positiva e abre espaço para que a própria área de contabilidade permita o desenvolvimento e a coexistência de estudos que produzam conhecimentos de outra natureza, paralelamente aos dominantes.

A possibilidade apontada pode ser fortalecida se considerarmos o estudo realizado por Frezatti, Nascimento e Junqueira (2009). Estes autores desenvolveram um ensaio teórico para discutir se o monoparadigma econômico - que utiliza exclusivamente a teoria neoclássica para explicar fenômenos contábeis - seria suficiente para atender questões de pesquisa em contabilidade gerencial. O debate proposto pelos autores suscita reflexões a respeito da dicotomia normativista versus positivista, e da importância de abordagens econômicas 
neoclássicas e não econômicas - como psicologia, sociologia e economia política - para o desenvolvimento da contabilidade gerencial. Por fim, os autores concluem que o monoparadigma pode ser prejudicial por limitar o crescimento da área de contabilidade gerencial. Ao mesmo tempo, recomendam que os pesquisadores subordinem a plataforma metodológica à questão de pesquisa, e não tenham o ímpeto de simplesmente repudiar o mainstream, mas estejam abertos a novas abordagens que proporcionem solução à questão de pesquisa.

Portanto, seguindo a posição dos referidos autores construímos, ao longo do presente ensaio, uma argumentação que reconhece as possibilidades de desenvolvimento de perspectivas outras, se ampliarmos, no Brasil, o diálogo com pesquisadores europeus. Fora do contexto norte-americano, a adoção de perspectivas não dominantes tem sido profícua para a produção contábil gerencial. Segundo Lukka (2010, p. 113), o número de artigos submetidos para as conferências europeias e seminários tem sido proporcionalmente maior, "assim como diversas conferências, alguns jornais de alta qualidade publicam todos os tipos de pesquisa contábil gerencial".

Diante desse quadro, o presente ensaio teórico tem o objetivo de revisitar as diferentes possibilidades epistemológicas em contabilidade, de forma a apontar como contribuições de abordagens interpretativas e críticas podem enriquecer a construção do conhecimento em contabilidade gerencial no contexto brasileiro. A relevância do presente artigo está em mostrar como a construção do conhecimento em contabilidade gerencial pode abarcar um somatório de perspectivas diferentes, de forma a tornar esse conhecimento consistentemente mais abrangente e mais plural. A tese central do texto é que, embora pesquisas mainstream tenham contribuído e certamente continuem a contribuir no futuro para o conhecimento sistematizado em termos de contabilidade gerencial, o incremento de outras perspectivas ontológicas e metodológicas irá descortinar novas possibilidades para pesquisa, além daquelas usualmente utilizadas.

Assim, a contribuição deste texto está em: i) ampliar o quadro de trabalhos que convocam os pesquisadores brasileiros a aprofundar o debate epistemológico em contabilidade; ii) sinalizar aos pesquisadores e aos programas a amplitude de oportunidades que se apresentam ao serem exploradas diferentes perspectivas de pesquisas; iii) descortinar limitações de argumentos favoráveis à redução de pluralismo em nome de vantagens epistêmicas ou metodológicas de uma perspectiva, ou forma de conhecimento, em detrimento de diversas outras.

Além dessa introdução, o artigo possui mais cinco partes. A segunda seção apresenta as abordagens de pesquisa em contabilidade por meio das recentes discussões sobre paradigmas. A terceira seção discorre sobre a contabilidade gerencial sob a perspectiva mainstream e as limitações às influências da economia neoclássica como principal elemento. $\mathrm{Na}$ quarta, ao revisitar as abordagens alternativas nos estudos em contabilidade gerencial, busca-se identificar as possíveis contribuições de tais alternativas e evidenciar como sua presença ou ausência pode direcionar a profundidade do conhecimento contábil gerencial. A quinta seção do artigo aponta para a construção do conhecimento, no contexto brasileiro, a partir de abordagens dentro e fora do mainstream; e evidencia a carência de pesquisas sob uma perspectiva diferente daquela amplamente incentivada pela academia norte-americana. Por fim, são traçadas considerações finais visando a contribuir para o debate, no Brasil, da contabilidade como uma ciência social aplicada.

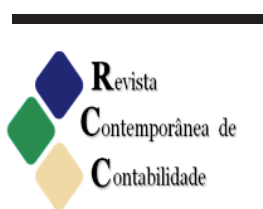

ISSN 2175-8069, UFSC, Florianópolis, v. 13, n. 28, p. 99-122, jan./abr. 2016 


\section{Abordagens de Pesquisa em Contabilidade}

Os contornos da pesquisa em contabilidade, sob a perspectiva de Smith (2011), estão delineados em torno de três principais abordagens de pesquisa, considerando as hipóteses de investigação, o processo e os resultados. Essas três principais abordagens seriam: abordagem positiva, abordagem interpretativa e abordagem crítica.

Para Smith (2011), a abordagem positiva é modelada por estudos clássicos com base nas ciências físicas. A realidade é unitária e só pode ser compreendida por métodos empíricos e analíticos. A observação é feita a partir de regras claras e não ambíguas. O resultado da pesquisa compreende evidências e leis generalizáveis, as quais não são afetadas por contextos de produção e consumo de conhecimento. A objetividade depende da remoção de erro e viés relacionados com a lógica da observação e medição. Os interesses inerentes a esse tipo de pesquisa são previsão e controle, conhecimento tecnicamente explorável, e explicação.

Segundo o autor, por outro lado, a abordagem interpretativa é modelada por estudos históricos, literários e existenciais, nos quais o entendimento subjetivo dos indivíduos é significativo. Para essa abordagem há múltiplas realidades, que requerem vários métodos para compreendê-las. A base dos dados são os significados, de forma que significado precede lógica e fato. A observação é feita por meio de habilidades sociais, linguísticas e cognitivas do pesquisador. O resultado da pesquisa é o conhecimento, que é dependente do processo de descoberta. Os interesses inerentes à pesquisa interpretativa são compreender, no nível da linguagem ordinária e ação, e descobrir os significados e crenças subjacentes às ações dos outros.

Já a abordagem crítica é modelada por estudos marxistas e interpretativos que incidem sobre os insights e julgamentos dos sujeitos. Para esta abordagem há múltiplas realidades que são problemáticas, feitas através de comunicação distorcida. Os significados são encontrados em linguagem e comportamento social, e eles precedem a lógica e a verdade. A observação é feita por meio de métodos interpretativos, acrescidos de autorreflexão crítica acerca dos motivos de observação. O resultado da pesquisa é o conhecimento que se insere no quadro interpretativo, mas que também serve o objetivo de auxiliar a libertação e entendimento pessoal, e emancipação das forças que limitam a independência racional dos indivíduos. Os interesses inerentes à pesquisa crítica são os interesses interpretativos e aqueles subjacentes a outras formas de investigação.

A partir de uma postura similar à Smith (2011), Ryan et al. (2002) apresentam uma discussão sobre as filosofias alternativas para pesquisa em contabilidade. A partir dos trabalhos de Tomkins e Groves (1983) e Hopper e Powell (1985), os autores destacam que os pressupostos ontológicos referem-se a seis maneiras possíveis de ver o mundo. Nesse sentido, Tomkins e Groves (1983) destacam que a realidade pode ser aceita como: i) uma estrutura concreta; ii) um processo concreto; iii) um campo contextual da informação; iv) um discurso simbólico; v) uma construção social; vi) uma projeção da imaginação humana. Tais perspectivas de mundo tornam o método científico inapropriado para determinadas pesquisas que adotem uma visão mais subjetiva (realidade como imaginação) que objetiva (realidade como estrutura concreta) no campo das ciências sociais. Do ponto de vista epistemológico, portanto, métodos para obter conhecimento serão diferentes e estarão relacionados com diferentes pressupostos ontológicos adotados. 
Nesse sentido, devemos compreender a existência de um continuum subjetivo-objetivo para apresentar uma taxonomia em pesquisa contábil inspirada nas dimensões propostas por Burrell e Morgan (1979). Hopper e Powell (1985) discorrem sobre o método de ciência dominante em pesquisa contábil, delineando três categorias de pesquisa normalmente adotadas em contabilidade: mainstream, interpretativa e crítica (Figura 1).

Figura 1 - Taxonomia de Hopper e Powell para pesquisa em contabilidade

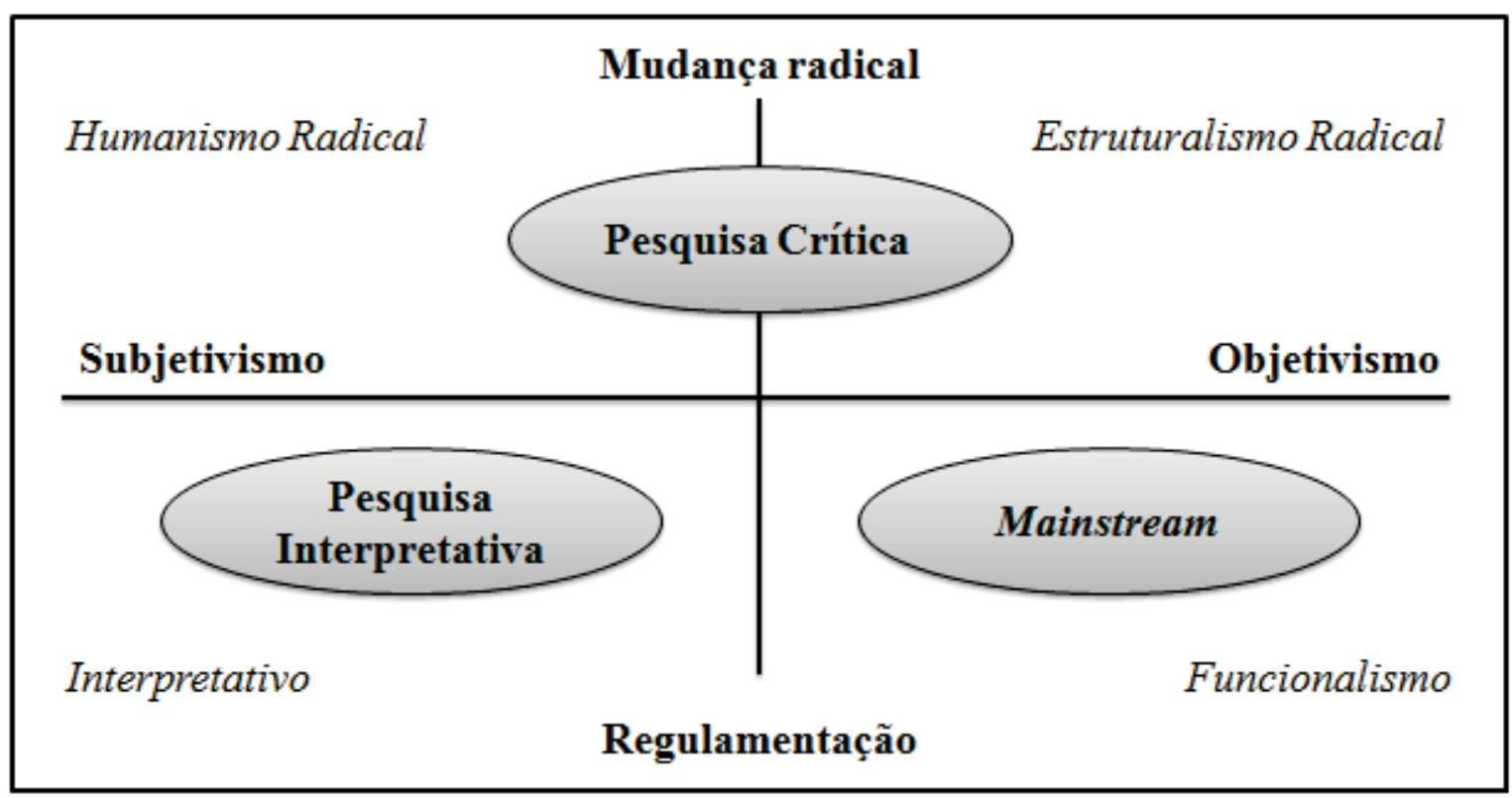

Fonte: Ryan et al. (2002, p. 40).

Esta taxonomia permite discutir as diferentes dimensões de ontologia, epistemologia, natureza humana e metodologia, de maneira que os extremos não representam dicotomias, mas há, entre eles, posições intermediárias, e refletiriam uma multiplicidade de formas de conhecimento relevantes. As três categorias de pesquisa em contabilidade diferem no que se refere a crenças sobre o conhecimento, sobre a realidade social e sobre o relacionamento entre teoria e prática, gerando um cenário que acomoda possibilidades plurais de conhecimento (Quadro 1).

Para tal, seguimos a argumentação de Laughlin (1995), que destaca ser mister que pesquisadores em contabilidade reconheçam que há uma série de abordagens alternativas disponíveis, vinculadas a filósofos sociais-chave, ainda não explorados na área. Ao discorrer sobre questões teóricas e metodológicas em pesquisa contábil, o autor assinala que "há uma certa vantagem e importância de fazer escolhas deliberadas sobre estas questões antes de realizar qualquer estudo" (LAUGHLIN, 1995, p. 65). Concordamos com a afirmação deste autor, de que toda pesquisa empírica será parcial, portanto, o pesquisador deve considerar com clareza as distorções e exclusões de sua escolha antes de se lançar a campo. 
Quadro 1 - Pressupostos ontológicos e epistemológicos de pesquisa contábil Mainstream, Interpretativa e Crítica

\begin{tabular}{|c|c|c|c|}
\hline & $\begin{array}{c}\text { Pesquisa contábil } \\
\text { mainstream }\end{array}$ & $\begin{array}{c}\text { Pesquisa contábil } \\
\text { interpretativa }\end{array}$ & Pesquisa contábil crítica \\
\hline $\begin{array}{c}\text { Crenças } \\
\text { sobre o } \\
\text { conhecimento }\end{array}$ & $\begin{array}{l}\text { "Teoria e observação são } \\
\text { independentes. Métodos } \\
\text { quantitativos são } \\
\text { preferidos ao proporcionar } \\
\text { generalizações". }\end{array}$ & $\begin{array}{l}\text { "Teoria fornece } \\
\text { explicações das } \\
\text { intenções humanas. Sua } \\
\text { adequação é assegurada } \\
\text { por consistência lógica e } \\
\text { interpretação subjetiva". }\end{array}$ & $\begin{array}{l}\text { "Critérios para julgar teorias são } \\
\text { sempre temporais e ligados ao } \\
\text { contexto. Objetos sociais somente } \\
\text { são entendidos por meio do } \\
\text { estudo de sua evolução dentro da } \\
\text { totalidade das relações". }\end{array}$ \\
\hline $\begin{array}{c}\text { Crenças } \\
\text { sobre a } \\
\text { realidade } \\
\text { física e social }\end{array}$ & $\begin{array}{l}\text { "Realidade empírica é } \\
\text { objetiva e externa ao } \\
\text { sujeito/pesquisador. Atores } \\
\text { são objetos passivos e } \\
\text { racionalmente possuem } \\
\text { objetivos assumidos. } \\
\text { Sociedade e organizações } \\
\text { são estáveis e } \\
\text { comportamento } \\
\text { disfuncional é gerenciado } \\
\text { por sistema se controle". }\end{array}$ & $\begin{array}{l}\text { "Realidade é socialmente } \\
\text { criada e objetivada por } \\
\text { meio da interação } \\
\text { humana. A ação humana } \\
\text { é intencional e tem } \\
\text { significado no contexto } \\
\text { social e histórico. A } \\
\text { ordem social é suposta e } \\
\text { os conflitos mediados } \\
\text { por meio de significados } \\
\text { compartilhados". }\end{array}$ & $\begin{array}{l}\text { "Realidade empírica é } \\
\text { caracterizada como objetiva, mas } \\
\text { é transformada e reproduzida } \\
\text { através da interpretação subjetiva. } \\
\text { Intenções humanas e } \\
\text { racionalidade são aceitas, mas } \\
\text { devem ser criticamente analisadas } \\
\text { porque o potencial humano é } \\
\text { alienado pela falsa consciência e } \\
\text { ideologia. O conflito social é } \\
\text { endêmico". }\end{array}$ \\
\hline $\begin{array}{c}\text { Relação entre } \\
\text { a teoria e a } \\
\text { prática } \\
\text { contábil }\end{array}$ & $\begin{array}{l}\text { "A contabilidade está } \\
\text { preocupada com os meios } \\
\text { e não fins, e as estruturas } \\
\text { institucionais existentes } \\
\text { são aceitas como dadas" }\end{array}$ & $\begin{array}{l}\text { "A teoria contábil busca } \\
\text { explicar a ação e } \\
\text { entender como a ordem } \\
\text { social é produzida e } \\
\text { reproduzida". }\end{array}$ & $\begin{array}{l}\text { "Teoria tem um imperativo } \\
\text { crítico; em particular a } \\
\text { identificação e a remoção da } \\
\text { dominação e praticas } \\
\text { ideológicas". }\end{array}$ \\
\hline
\end{tabular}

Fonte: Elaborado a partir de Ryan et al. (2002, p. 41-43, passim).

As escolhas deliberadas dos pesquisadores, prévias à pesquisa empírica, quanto à abordagem escolhida e suas implicações de ordem epistemológica, remetem-nos a reconhecer que as discussões sobre paradigmas tratam também de suas parcialidades.

Paradigmas ajudam-nos a ver outras e novas possibilidades para conduzir nossas pesquisas. Ser ignorantes ou não refletir sobre as nossas bases filosóficas, metodológicas e teóricas, pode nos fazer eficientes 'dentro da caixa', mas leva o risco de vermos apenas árvores e não florestas inteiras (LUKKA, 2010, p.112).

Embora a contabilidade não consista em uma disciplina de único paradigma, Lukka (2010) destaca que, na prática, ela é dominada por um único paradigma, ou seja, prevalece a pesquisa contábil dominante, que é amplamente fundamentada na economia, e especialmente dominante na América do Norte.

A estrutura apresentada por Burell e Morgan (1979) há muito vem suscitando acalorados debates. Por isso, consideramos importante esclarecer que a área de contabilidade também se posiciona ante críticas e limitações do modelo destes autores. Segundo Lukka (2010), os embates na comunidade científica ao redor de paradigmas de pesquisa não é algo recente. Já na década de 1970 pesquisadores debatiam intelectualmente sobre a existência de paradigmas em contabilidade e se esta é uma disciplina multiparadigmática. Essa natureza multiparadigmática voltou à discussão com pesquisadores como Tomkins e Groves (1983) e Chua (1986), a partir da taxonomia proposta por Burrel e Morgan em 1979.

Portanto, concordamos com Iudícibus et al. (2011), por considerar a contabilidade como ciência social aplicada que se compromete com outras ciências sociais, no sentido de 
estimular a multi e interdisciplinaridade em prol do desempenho de sua missão. Neste sentido, cabe destacar que pesquisa contábil, em especial a contabilidade gerencial, tem apresentado base teórica consistentemente fundamentada em estudos organizacionais (REIS; PEREIRA, 2007). Portanto, a interdisciplinaridade em contabilidade gerencial deve considerar as diversas epistemologias em estudos organizacionais.

\title{
3 Trajetórias Paradigmáticas em Contabilidade Gerencial
}

O conceito convencional de contabilidade gerencial - área da contabilidade que busca conhecer as necessidades dos gestores - é diferente do dominante conceito no qual a contabilidade gerencial reporta não apenas informações financeiras, mas outros tipos de informações necessárias para o controle dos objetivos da organização.

$\mathrm{O}$ atual mainstream da pesquisa em contabilidade gerencial é composto por pesquisas normativas e positivas, ambas de base econômica neoclássica, e também por pesquisas empíricas com base em teorias comportamentais e organizacionais funcionalistas (LUKKA, 2010; BAXTER; CHUA, 2003, RYAN et al. 2002). A partir da tentativa de Ittner e Larcker (2001) em apontar razões para as falhas na construção do conhecimento na área, o mainstream em contabilidade gerencial foi suscitado pelo questionamento de Zimmermman (2001, p. 411) que, em discordância às explicações de Ittner e Larcker (2001), afirmou que

\begin{abstract}
A pesquisa empírica em contabilidade gerencial falhou em produzir um substantivo corpo de conhecimento cumulativo. Essa literatura não amadureceu além da descrição da prática para o desenvolvimento e o teste de teorias que expliquem as práticas observadas, como em outras áreas da pesquisa contábil. Embora a falta de dados publicamente disponíveis seja apresentada como o motivo para o estado subdesenvolvido dessa literatura, este não é o único motivo. Outras suposições incluem: seu caráter indutivo, os incentivos aos pesquisadores, o uso de quadros de análise não baseados em economia, a falta de teorias empiricamente testáveis, e sua ênfase em tomada de decisão e não em controle.
\end{abstract}

A percepção de Zimmermman foi refutada por diversos pesquisadores, entre eles Luft e Shields (2002) e Hopwood (2002), os quais contestam questões como a supremacia econômica defendida por Zimmermman e a forma como este autor entende que a contabilidade gerencial lança mão de teorias. Pesquisas em contabilidade gerencial tem uma permanência de citação estável nos jornais internacionais em relação a outras áreas da contabilidade. Em torno de $50 \%$ destes artigos são baseados na economia neoclássica, sistemas de controle gerencial são um tema de destaque dentro dos tópicos de contabilidade gerencial e, além disso, pesquisadores de contabilidade gerencial têm sido chamados a permanecer abertos para explorar os quadros intelectuais que outras disciplinas têm a oferecer (MENSAH, HWANG, WU, 2004; ITTNER; LARCKER, 2002).

Ryan et al. (2002) traçam uma linha temporal da pesquisa em contabilidade gerencial sob as abordagens normativa e positiva. Segundo eles, a contabilidade gerencial passou a ser vista como assunto acadêmico a partir das décadas de 1950-1960, e o desenvolvimento da literatura contábil gerencial, nesse período, emplacou o tema diferentes custos para diferentes propósitos, com ênfase nas decisões de curto prazo. Na primeira metade do século XX, a contabilidade preocupava-se com os custos do produto e o controle de mão de obra direta, 
materiais diretos e custos indiretos. Na segunda metade do século XX, algumas técnicas foram desenvolvidas para resolver problemas de custos precisos, e a preocupação da contabilidade foi transferida para a tomada de decisões.

A pesquisa contábil normativa foi toda desenvolvida a partir do quadro econômico neoclássico, e todo o contexto de tomada de decisões era analisado pelos pesquisadores a partir de premissas da teoria neoclássica. Desta forma, a janela tradicional de contabilidade gerencial normativa aceitava que: i) tomadores de decisão são maximizadores de lucros; ii) tomadores de decisão dispõem, sem custo e com certeza, de todas as informações disponíveis; iii) tomadores de decisão podem ser isolados individualmente de outros decisores dentro da organização. Inúmeras técnicas quantitativas e modelos de decisão foram desenvolvidos para auxiliar os tomadores de decisão, e formavam um bojo de análise formal para a contabilidade gerencial. Especialmente na década de 1960, técnicas matemáticas, como custo-volume-lucro, modelos de estimação de custos, nível de aprendizagem; e modelos construídos sob as premissas econômicas descreviam como as decisões deveriam ser tomadas. O raciocínio dedutivo era explicita e amplamente utilizado, visto que os modelos e técnicas prescreviam o que deveria acontecer (RYAN et al., 2012; BAKER; BETTNER, 1997).

$\mathrm{Na}$ década de 1970, os pesquisadores passaram a refinar e expandir os modelos que haviam sido desenvolvidos na década de 1960, sob os pressupostos de baixo custo de informações, único proprietário ou tomador de decisões e ambiente de certeza. Os modelos se tornaram altamente complexos por conta da inserção da variável incerteza. Em condições de incerteza, custo e valor da informação tornaram-se importantes, tornando evidentes as limitações de modelos desenvolvidos sob as condições de certeza e a complexa natureza da incerteza nas tomadas de decisões.

No final dos anos de 1970 e início da década de 1980, observou-se um gap entre a teoria e a prática, gerando: i) crescente número de estudos sobre a natureza da contabilidade gerencial; e ii) mudanças na metodologia da pesquisa em contabilidade gerencial. Ryan et al. (2002) destacam que a mudança de ênfase - pesquisa normativa para positiva - ocorreu porque os pesquisadores constataram que técnicas simples poderiam ser ótimas, quando levados em consideração os custos e os benefícios para obter a informação necessária.

A abordagem positiva em contabilidade gerencial, cuja preocupação está em explicar e prever os fenômenos contábeis, ganhou força a partir da década de 1980 (IUDÍCIBUS et al, 2011). Sob essa abordagem, os pesquisadores estão interessados nas razões para as práticas contábeis adotadas, os modelos continuam sendo utilizados, mas não com o caráter de prescrever, mas de prever. Nessa nova abordagem são relaxadas as premissas pertinentes à certeza e ao custo da informação; no entanto, a contabilidade gerencial continua a considerar os tomadores de decisões como racionais e maximizadores de utilidades pessoais. A teoria da agência (JENSEN; MECKLING, 1976) é utilizada de forma predominante para reconhecer a separação entre o proprietário e o agente tomador de decisões, bem como para explicar o comportamento oportunista deste; e a abordagem econômica continua sendo o principal pano de fundo para os pesquisadores.

$\mathrm{Na}$ abordagem comportamental em contabilidade gerencial, teorias com pressupostos diferentes da teoria econômica neoclássica tornaram-se amplamente utilizadas, notadamente teorias comportamentais e teorias organizacionais funcionalistas (LUKKA, 2010; RYAN et al., 2012). Uma vez que o objetivo destas pesquisas é prever o comportamento humano, seu caráter é naturalmente normativo e a metodologia adotada é empírica, isto é, busca-se conhecer um comportamento considerado disfuncional em relação aos objetivos estabelecidos 
para a organização para, então, poder controlá-lo melhor. Nesse processo, o comportamento é observado, mensurado e categorizado.

É justamente a metodologia empírica como característica essencial que confere às pesquisas em contabilidade comportamental o status de pertencentes ao mainstream (MODELL, 2010). Ryan et al. (2002, p. 82) destacam que as pesquisas em contabilidade comportamental "não representam uma significante mudança na metodologia" em pesquisa contábil, e o mérito desta abordagem está em abrir outras áreas de estudos para os pesquisadores em contabilidade, ampliando as bases da disciplina. Por meio desta abordagem, os pesquisadores em contabilidade gerencial exploram a dimensão do tomador de decisão individual, os estudos são com base na ciência do comportamento, teoria da decisão e na psicologia cognitiva; ou a dimensão organizacional, em que os estudos são com base nas teorias organizacionais funcionalistas, com ênfase na teoria contingencial e relações entre ambientes organizacionais, comportamentos e variáveis contábeis (BAXTER; CHUA, 2003; RAYAN et al., 2012).

\subsection{Principais Críticas ao Mainstream}

A pesquisa contábil positiva está calcada sobre o cerne da teoria neoclássica de racionalidade econômica (MODELL, 2010; BAKER, BETTNER, 1997). Ryan et al. (2002, p. 78) destacam que dois postulados da teoria neoclássica - i) maximização da utilidade; ii) teoria dos mercados como a localização estrutural onde as transações ocorrem - têm sido severamente criticados e, em resposta, os economistas contra argumentam em termos metodológicos, afirmando que "o realismo dos pressupostos de uma teoria é irrelevante; o importante é a habilidade da teoria para predizer o fenômeno econômico". Isto significa que, embora a teoria econômica não explique o comportamento dos agentes individuais, ela é capaz de prever comportamento agregado.

Ryan et al. (2002) sinalizam as limitações da pesquisa contábil gerencial de abordagem positiva. Os autores explicam que a contabilidade gerencial se preocupa com o comportamento de empresas individuais e de indivíduos dentro destas empresas; neste sentido, os economistas admitem que existem limitações da teoria neoclássica para esse nível de estudo. A teoria neoclássica é apta para prever em nível de mercado e não em nível de indivíduo, pois foi desenvolvida para prever tendências gerais de comportamento econômico, sem ter a intenção de explicar como indivíduos se comportam ou deveriam se comportar. Sob estas considerações, a teoria econômica neoclássica torna-se inadequada para os fins pretendidos pela contabilidade gerencial. Apesar dessa ampla limitação metodológica, a pesquisa contábil gerencial positiva, sob os pressupostos neoclássicos, é uma abordagem dominante nas escolas de contabilidade.

As limitações metodológicas da abordagem comportamental são as mesmas presentes na abordagem positiva baseada na economia: "eles podem prever tendências gerais, mas não podem explicar processos por meio dos quais os sistemas de contabilidade gerencial evoluem em determinadas organizações" (RYAN et al., 2002, p. 84). Alguns autores argumentam que tal metodologia, sem excluir a possibilidade de exceções, utiliza correlações provenientes de estatísticas significantes para generalizar relacionamentos, e gera um problema para o projetista do sistema de contabilidade, visto que estudos transversais, embora identifiquem as 
relações em dado momento, não conseguem explicar como elas vieram a existir, tal explicação só ocorreria em estudos longitudinais (RYAN et al., 2002; MODELL, 2010).

Smith (2011) faz um paralelo, no qual uma mudança de paradigma em pesquisa contábil envolve alguma revolução no quadro de teorias existentes, pelo fato de elas não mais poderem lidar com o número de evidências existentes. Segundo Baker e Bettner (1997), pesquisadores contábeis podem sofrer resistências para questionar o paradigma existente.

\section{Abordagens Possíveis para a Contabilidade Gerencial}

A inserção de teorias sociais para a contabilidade gerencial trouxe uma mudança significativa em termos metodológicos a partir da década de 1980 (BAXTER; CHUA, 2003; RYAN et al, 2002). No contexto internacional, os pesquisadores ampliaram a contabilidade gerencial para um contexto social diferente daquele até então adotado, e inseriram teorias a partir das ideias de teoristas sociais como Giddens, Foucault, Habermas e Latour, permitindo uma proliferação de alternativas em pesquisa contábil e favorecendo embates teóricos entre diversas abordagens (LAUGHLIN, 1995; LEE; HUMPHREY, 2006; RYAN et al. 2002).

Uma gênese da base teórica de pesquisas empíricas em contabilidade gerencial elaborada por Luft e Shields (2007), a partir de publicações em periódicos internacionais, mostra como as teorias em ciências sociais têm influenciado os temas de pesquisa em contabilidade gerencial (Quadro 2). Utilizar diversas formas de triangulação teórica para os estudos em contabilidade gerencial, a partir de teorias que compartilhem pressupostos epistemológicos compatíveis, tem permitido o avanço na compreensão das multifacetadas realidades organizacionais, e requer que os pesquisadores sejam conscientes de sua reflexividade na pesquisa (HOQUE; COVALESKI; GOONERATNE, 2015). A triangulação teórica, a partir de teorias com pressupostos epistemológicos divergentes, também tem sido considerado um caminho possível, mas essa forma ambiciosa tem suscitado debates acalorados em torno da legitimidade e validação de investigações, que transitam entre paradigmas funcionalistas e interpretativos (MODELL, 2009, 2010, 2015).

Quadro 2 - Temas de pesquisa e perspectivas teóricas em contabilidade gerencial

\begin{tabular}{|c|l|}
\hline $\begin{array}{c}\text { Temas de pesquisas empíricas em } \\
\text { contabilidade gerencial }\end{array}$ & \multicolumn{1}{|c|}{ Perspectivas teóricas sociais utilizadas } \\
\hline $\begin{array}{c}\text { Causas e efeitos do orçamento no nível dos } \\
\text { indivíduos }\end{array}$ & $\begin{array}{l}\text { - Relações humanas (MAYO, 1933; LEWIN, 1948); } \\
\text { - Psicologia social das organizações (MCGREGOR, 1960; } \\
\text { LIKERT, 1961; VROOM, 1964). }\end{array}$ \\
\hline $\begin{array}{c}\text { Causas e efeitos do orçamento ao nível } \\
\text { organizacional e de subunidades; } \\
\text { Informações para planejamentos e } \\
\text { controle; }\end{array}$ & $\begin{array}{l}\text { Teoria Contingencial das organizaços (BURS; STALKER, } \\
\text { 1961; LAWRENCE; LORSCH, 1967; THOMPSON, 1967; } \\
\text { GALBRAITH, 1973). }\end{array}$ \\
\hline $\begin{array}{c}\text { Implementação de mudanças contábeis } \\
\text { Medidas de desempenho e incentivos }\end{array}$ & $\begin{array}{l}\text { - Informações econômicas e teoria de agência (MARSCHAK; } \\
\text { RADNER 1972; HOLMSTRÖM, 1979). }\end{array}$ \\
\hline Contracting and control: microprocesses; & $\begin{array}{l}\text { RADNER, 1972; HOLMSTRÖM, 1979); } \\
\text { - Psicologia Social (TAYLOR et al 2003); } \\
\text { - Psicologia Cognitiva (NEWELL; SIMON, 1972; TVERSKY; } \\
\text { KAHNEMAN, 1974) }\end{array}$ \\
\hline
\end{tabular}




\begin{tabular}{|c|c|}
\hline Julgamentos individuais e decisões & $\begin{array}{l}\text { - Informações econômicas e Teoria de agência (MARSCHAK; } \\
\text { RADNER, 1972; HOLMSTRÖM, 1979); } \\
\text { - Psicologia Cognitiva (Newell; Simon, 1972; Tversky; } \\
\text { Kahneman, 1974). }\end{array}$ \\
\hline $\begin{array}{l}\text { Contabilidade gerencial em seu contexto } \\
\text { histórico e social }\end{array}$ & $\begin{array}{l}\text { - Economia Política (BRAVERMAN, 1974); } \\
\text { - Sociologia Institucional (BERGER; LUCKMANN, 1967; } \\
\text { MEYER; ROWAN, 1977); } \\
\text { - Modelos Políticos de organizações (PFEFFER, 1981); } \\
\text { - Teoria do Discurso (FOUCAULT; 1972, 1979). }\end{array}$ \\
\hline $\begin{array}{l}\text { Processos de mudanças organizacionais e } \\
\text { relações de realidades financeiras e } \\
\text { operacionais }\end{array}$ & $\begin{array}{l}\text { - Modelos Políticos de organizações (PFEFFER, 1981); } \\
\text { - Teoria do Discurso (FOUCAULT, 1972, 1979); } \\
\text { - Etnografia (GEERTZ, 1973); } \\
\text { - Science studies (LATOUR, 1987). }\end{array}$ \\
\hline
\end{tabular}

Fonte: Com base em Luft e Shields (2007).

Ainda no contexto internacional, de 1976 a 1999 existiam pelo menos sete correntes de pesquisa em contabilidade gerencial sob lentes alternativas. Baxter e Chua (2003) identificaram e nomearam estas correntes de: i) escola de concepção não racional; ii) pesquisa naturalista; iii) alternativa radical; iv) teoria institucional; v) teoria da estruturação; vi) abordagem Foucaultiana; vii) abordagem Latouriana. No Quadro 2 podemos observar o tom teórico que as pesquisas em contabilidade receberam a partir das teorias sociais, as quais contribuíram para que a contabilidade gerencial adotasse um novo perfil e sentido. Com base em Prassad (2005), nós complementamos estas correntes relacionadas por Baxter e Chua (2003) com outras abordagens possíveis para análise de fenômenos contábeis, as quais ganharam notoriedade nos estudos gerenciais e organizacionais nos últimos anos, e estão relacionadas com perspectivas interpretativas, críticas e pós-estruturalistas:

\section{Quadro 3 - Abordagens alternativas para pesquisas em contabilidade gerencial}

Abordagens em Contabilidade Gerencial identificadas por Baxter e Chua

A escola de concepção não racional é uma perspectiva alternativa que questiona os pressupostos da racionalidade nas escolhas organizacionais. Essa escola sugere que: "metas organizacionais são obscruras e instáveis; a procura é local e limitada; o processo de análise e escolha pode ser politicamente motivado, de natureza incremental, rotinizado pela aplicação de procedimentos, ou mais fortuito do que considerado".

A abordagem naturalística é uma perspectiva alternativa que busca investigar as práticas contábeis gerenciais no contexto diário da organização. Seu corpo de pesquisa é fragmentado, pois cada estudo trata um aspecto singular da prática contábil.

A alternativa radical é uma perspectiva alternativa que busca destacar, sob as ideias de Marx, da Escola de Frankfurt e da literatura do processo de trabalho, como a "contabilidade gerencial está implicada na criação e perpetuação de uma sociedade desigual”. Para este tipo de pesquisa, justiça, educação, saúde e outros recursos "não estão distribuidos sobre as bases necessárias". Sob essa abordagem os investigadores trabalham de duas maneiras:" primeiro mobilizam a retórica crítica sobre contabilidade gerencial; segundo, usam teorias radicais para orientar as investigações empíricas".

A teoria institucional é uma perspectiva alternativa que não vê o comportamento coletivo como um agregado de ações individuais. Sob essa abordagem, o comportamento coletivo é explicado por regras socialmente geradas, "há um ambiente técnico e vários ambientes institucionalizados". Assim, as práticas de contabilidade gerencial são influenciadas pela complexidade dos múltiplos ambientes institucionalizados na organização.

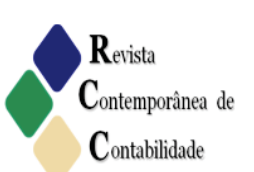


A teoria da estruturação é uma perspectiva alternativa que, sob a teoria da estruturação de Giddens, preocupa-se com a capacidade de escolhas individuais e a reprodução de estruturas sociais (regras e recursos). Segundo esta teoria, "os indivíduos podem agir de maneira diferente das normas e regras prevalecentes." Giddens também destaca como o comportamento humano impacta o contexto da sociedade e como a sociedade marca o comportamento humano.

A abordagem Focaultiana é uma perspectiva alternativa que, sob as obras de Foucault, tem gerado novas histórias da contabilidade gerencial. A partir do tema arqueologia de Foucault, pesquisadores desafiaram as tecnologias de contabilidade gerencial e suas origens, considerando as formas complexas e imprevisíveis nos discursos e estruturas intitucionais. A partir da obra controle e docilidade são feitas contruções sobre controle em contabilidade gerencial, e "controle é visto como um reflexo de teias institucionalizadas".

A abordagem Latouriana é uma perspectiva alternativa que, sob as obras de Latour, está preocupada em "compreender as tecnologias de contabilidade no contexto de redes humanas e não-humanas". Para alguns destes pesquisadores, os números contábeis são construídos para aparentar fatos e acomodar interesses. Argumenta-se, ainda, que "os números de contabilidade gerencial facilitam a incorporação de valores partidários nas rotinas diárias e funcionamento organizacional”.

Outras abordagens (tradições interpretativas, críticas, pós) utilizadas em estudos gerenciais e organizacionais

A abordagem praxeológica de Bourdieu é uma perspectiva alternativa que emerge da teoria da prática social de Bourdieu, através da qual a ação humana é uma reconstrução das estruturas simbólicas de significado. Bourdieu "oferece uma sociologia do poder simbólico que examina a relação entre a cultura, estrutura social e ação." Para Bourdieu, o sistema simbólico legitima a dominação. Ele argumenta que "existem interesses estratégicos ocultos utilizados por vários grupos sociais para maximizar os seus materiais e simbólicas vantagens". Em teoria, na prática de Bourdieu há uma luta contínua entre as classes, etnias e outros grupos e dinâmicas culturais dentro do processo social pelo diferentes recursos (tipos de capital) que os grupos possuem.

Feminismo é uma perspectiva alternativa que surgiu da preocupação com a invisibilidade e exploração de mulheres, mas atualmente é caracterizado por uma grande diversidade de estudos que se concentram, por exemplo, nas relações entre raça, religião, etnia, nacionalidade, educação das mulheres, igualdade de oportunidades, e discriminação salarial. Filosoficamente, esta abordagem é influenciado pelo marxismo, o existencialismo, psicologia relacional e pós-estruturalismo.

Pós-colonialismo/Decolonialismo é uma perspectiva alternativa que está engajada com a crítica e a resistência da modernidade ocidental. O pós-colonialismo tem a preocupação de identificar ações para resistir a quaisquer tentativas de colonialismo e neocolonialismo modernas. Neste sentido, as pesquisas discorrem sobre como colonizadores (por exemplo, culturas, países, organizações) influenciam a maneira de pensar, de agir e de trabalhar daqueles que são colonizados. Esta abordagem procura compreender e reavaliar o patrimônio colonial e "é extraordinariamente relevante para estudos de gestão e de organização, pois oferece uma explicação histórica alternativa para muitos negócios comuns que têm suas origens nas estruturas coloniais" (PRASSAD, 2005, p. 263).

Fonte: Elaborado com base em Baxter e Chua (2003, p. 98-102) e Prassad (2005, pp.13-75, 113-281).

Entre as inúmeras contribuições elencadas por Baxter e Chua (2003, pp. 98, 104, 105), podemos destacar, aqui, as advindas da escola de concepção não racional, que forjou "conexões inovadoras entre o sistema de informação contábil gerencial e o funcionamento organizacional", evidenciando que os sistemas de contabilidade gerencial são coercitivos, e que práticas de contabilidade gerencial padronizam pensamento e ação. Outras contribuições referem-se à compreensão de que "tecnologias de contabilidade gerencial não podem ser separadas da formação e exercício do poder nas organizações e na sociedade". As pesquisas 
de base Latourianas ilustraram "conexões que podem ser forjadas entre os interesses dos formuladores de políticas governamentais e particulares práticas de contabilidade gerencial". Adicionalmente, as pesquisas Focautianas, mostraram, por meio do estudo da institucionalização das teias de poder, como as tecnologias de contabilidade gerencial emergem, de forma não inocente, como oposição aberta aos interesses organizacionais.

O impacto de teorias sociais sobre a contabilidade tem sido indubitavelmente significante. Ryan et al. (2002) destacam que, a partir destas teorias, foi possível à contabilidade gerencial: "i) reavaliar a sua história; ii) mostrar sua natureza interessada, iii) ser desafiada quanto às reivindicações de neutralidade e racionalidade, iv) receber insights alternativos no que concerne à sua função para as organizações". No entanto, estes autores lamentam que, embora sejam notáveis estas contribuições, muitos pesquisadores em contabilidade gerencial utilizam as teorias sociais apenas para validar sua pesquisa e ilustrar práticas em contabilidade, fornecendo pouca reflexão sobre a teoria em si mesma e pequena interação entre a teoria e a pesquisa realizada (RYAN et al., 2002).

A interação entre teoria e prática ainda é um desafio na área contábil. Neste sentido, para que o uso de teorias sociais sob uma abordagem interpretativa seja mais profícuo, os pesquisadores precisariam buscar, como bem explana Modell (2010), uma relação entre o cotidiano e as dimensões de estrutura social em seu contexto social amplo, e examinar sua evolução temporal. A título de exemplo, Ryan et al. (2002) destacam que um estudo dessa natureza explora como a contabilidade é condicionada pelo sistema socioeconômico, como tal sistema fornece regras que estruturam certos tipos de comportamentos organizacionais, e como as regras emergem das práticas sociais dos participantes da organização. Estes autores destacam, ainda, que pesquisas contábeis interpretativas buscam entender o mundo social como ele é e, ainda que possam construir teorias para oferecer compreensão da estrutura social, não estão preocupadas em fornecer teorias preditivas. Scapens (2008) reforça essa linha de entendimento ao destacar que, quando o pesquisador localiza as práticas correntes de contabilidade em seus contextos históricos, econômicos, sociais e organizacionais, ele pode entender a contabilidade gerencial como uma prática social.

Os estudos interpretativos em contabilidade gerencial têm buscado desenvolver abordagens que superem a rígida distinção entre conhecimento objetivo e subjetivo (AHRENS, 2008). Assim, a realidade emerge de uma subjetividade criada e é objetivada pela interação humana intencional. Como argumenta Ahrens (2008), a contextualização da contabilidade gerencial evidencia mudança social objetiva por meio da ação de indivíduos ou grupos que impulsionam mudanças por rearranjos espaciais e desenvolvimentos conceituais, e as práticas de contabilidade gerencial são partes de ações concretas intencionais.

Diferentemente da dicotomia apoiada por Burrell e Morgan (1979), por meio da qual pesquisa interpretativa assume o sinônimo exclusivo um de estudo de caráter qualitativo, fenomenológico e naturalístico, a pesquisa interpretativa em contabilidade gerencial é aquela para o qual pesquisa interpretativa assume o sinônimo de "realidade emergente subjetivamente criada e objetivada no intercurso social" (AHRENS, 2008). Estes aspectos contribuem para que os estudos interpretativos em contabilidade gerencial não sejam puramente subjetivistas, como alguns defendem, pois a contabilidade gerencial interpretativa combina elementos subjetivos e objetivos para analisar os fenômenos.

Destarte, todo o potencial inerente à pesquisa em contabilidade, sob uma perspectiva interpretativa, necessita de destaque. Nas palavras de Scapens (2008), as pesquisas que vem 
sendo realizadas ainda carecem de maior relevância, e isto ocorre porque os pesquisadores em contabilidade interpretativa preocupam-se em explicar o que está acontecendo, e nessa busca chegam a explicações altamente teorizadas sob diferentes métodos e disciplinas a partir da utilização de teorias sociológicas, organizacionais, sociais, econômicas, políticas e antropológicas sociais. No entanto, as pesquisas têm impactado de forma muito limitada sobre o que realmente ocorre na prática, no dia-a-dia organizacional.

Seguindo o raciocínio de Scapens (2008), os pesquisadores brasileiros poderiam alcançar relevância para suas pesquisas interpretativas em contabilidade gerencial de diversas maneiras: i) buscando intervir em organizações individuais por meio de pesquisa intervencionista, que combine o conhecimento teórico dos pesquisadores com o conhecimento derivado da experiência de praticantes da contabilidade; ii) preocupando-se com consequências políticas e sociais da contabilidade nas organizações modernas; iii) redigindo manuscritos críticos a respeito de soluções gerenciais e técnicas oferecidas por gurus gerenciais e consultores, comentando, questionando ou alterando, discorrendo sobre os problemas potenciais de tais soluções; iv) desenvolvendo projetos e programas para debater, ensinar e comunicar (via cursos de pós-graduação, debates com categorias profissionais e com políticos, publicação de artigos em jornais profissionais, por exemplo) aos executivos e praticantes, as questões identificadas pela pesquisa interpretativa.

Outra possibilidade para pesquisadores em contabilidade gerencial no Brasil é adotar uma abordagem crítica para estudar os fenômenos contábeis. Esta perspectiva de pesquisa requer que o pesquisador vá para além do entendimento dos processos sociais. As pesquisas críticas, como lecionam Ryan et al. (2002, p. 87), são uma abordagem na qual há uma firme preocupação com a criação de condições para que mudanças sociais sejam possíveis. Neste sentido, sob esta perspectiva, o pesquisador deve ampliar as condições da vida social, o que necessariamente envolve: i) explicar "porque práticas contábeis são tão próximas à busca de eficiência econômica e porque controle é percebido como atividade técnica em vez de um processo social", ii) habilitar-nos a "reconhecer com clareza que a própria natureza dos participantes organizacionais é tanto uma consequência dos modos existentes de controle organizacional como uma condição que aumenta a necessidade para controle". A abordagem crítica está preocupada tanto em conhecer quanto em intervir no mundo social (SMITH, 2011; RYAN et al., 2002).

O estudo de Neu, Cooper e Everet (2001) exemplifica dois casos de intervenção social. Os autores destacam que, dentro da escola de contabilidade crítica, há consenso sobre efeitos hegemônicos e distributivos da contabilidade, e nesse sentido "técnicas contábeis, números e discursos suportam a apropriação de valores excedentes de países periféricos". O reconhecimento destes efeitos tem estimulado pesquisadores críticos a "analisar e elucidar o funcionamento partidário da contabilidade dentro de conflitos sociais". Ao analisar dois episódios temporais e geograficamente específicos, os autores propõem algumas estratégias para que os pesquisadores de contabilidade crítica intervenham, não apenas realizando intervenções reativas: realizar um trabalho preparatório ideológico para definição do quadro discursivo, desenvolver visibilidade pública e capital cultural, desenvolver redes de aliados.

Roslender e Dillard (2003) argumentam que, no contexto internacional, a maioria dos pesquisadores contábeis críticos está dentro do mainstream em contabilidade e, desta forma, podem atuar como consultores e compartilhar suas competências. No entanto estes autores alertam que, para que haja evolução contábil crítica de força genuinamente alternativa, deve haver interação de disciplinas e subdisciplinas, com maior grau de envolvimento com os 
colegas da comunidade contábil em suas próprias arenas, por meio de conferências e revistas, e persuasão para que estes se envolvam com as atividades de contabilidade crítica.

A contabilidade, sob a perspectiva crítica, é considerada como meio e resultado dos arranjos sociais. De natureza interdisciplinar, ela trabalha para o interesse público, mas está carente de ações construtivas para se efetivar como tal (ROSLENDER; DILLARD, 2003). Ações junto à comunidade de pesquisa acadêmica, aos estudantes universitários e profissionais de contabilidade são exemplos de Roslender e Dillard (2003) aplicáveis aos pesquisadores em contabilidade gerencial, no Brasil, para explorar as prerrogativas que a pesquisa contábil crítica chama para si.

Por fim, Roslender e Dillard (2003, p. 345, passim) acreditam que, de uma perspectiva contábil crítica, "deficiências de contabilidade só podem ser consequências de profundas deficiências associadas com o interesse público". Para os autores, como a contabilidade nunca foi construída sob os interesses públicos, "a única forma de desenvolver uma contabilidade verdadeiramente habilitada está em instalar uma estrutura de acordos sociais suportados por uma filosofia de igualitarismo".

\section{Características da Pesquisa em Contabilidade Gerencial no Brasil}

As autoras deste artigo reconhecem que a formação do conhecimento em contabilidade gerencial não envolve apenas questões concernentes à publicação, também se atrela a como é direcionado o ensino via matrizes curriculares, e quais bases metodológicas e teóricas contribuirão para a propagação desse ensino no contexto brasileiro.

$\mathrm{Na}$ graduação, a disciplina de contabilidade gerencial ocupa em torno de $12 \%$ da carga de aula de cursos de contabilidade em algumas universidades. Os alunos têm uma grade curricular de contabilidade gerencial fortemente ancorada em Custos e Orçamentos, desdobrados em variações como acumulação de custos, preço de transferência e avaliação de desempenho. Controle organizacional parece ser um tema pouco abordado (SOUZA; BORGERT; RICHARTZ, 2012; MIRANDA, RICCIO, MIRANDA, 2013). Em algumas universidades, embora docentes e coordenadores considerem que a interdisciplinaridade seja importante para a contabilidade gerencial, os docentes estão pouco integrados, e os alunos também, em nível de pouca integração com pesquisa e extensão, revelam lacunas no conhecimento prévio necessário para o bom entendimento da disciplina (PADOAN, 2007).

Na pós-graduação, Cardoso, Oyadomari e Mendonça Neto (2007) mostraram que, no Brasil, a Positive Accounting exerce forte influência sobre a produção científica. Nos anos de 2002 a 2005, oriunda dos programas de pós-graduação Stricto Sensu, tal influência está concentrada especialmente nos programas da USP e FUCAPE, e as reflexões destes autores seguem no sentido de que a replicação de modelos desenvolvidos em grandes centros acadêmicos parece ser um caminho natural àqueles que voltarão às suas instituições de origem para exercer a docência. Portanto, torna-se desejável que estes pesquisadores foquem aspectos peculiares da realidade brasileira.

Diferente do que ocorre nos Estados Unidos, a formação de doutores em contabilidade, no Brasil, vem crescendo nos últimos anos, e a formação em contabilidade gerencial tem superado os números de formados em contabilidade financeira (LUNKES, et al., 2011). As universidades que ocupam uma posição de centralidade na construção do 
conhecimento em contabilidade gerencial são a USP-SP, a UFMG, a UFPE e a UFPR, o que sugere que a pesquisa em contabilidade gerencial está se fortalecendo e posicionando-se academicamente a partir dos Programas de Pós-Graduação Stricto Sensu conduzidos por essas instituições (CRUZ et al., 2010).

Em contraposição, a produção científica em contabilidade gerencial decresceu no período de 2002 a 2010. Lunkes et al. (2011) consideram que um fator para tal constatação pode ser o fato de as normas de contabilidade convergentes aos padrões internacionais provocarem um aumento de pesquisas em contabilidade financeira, e apontam outras possíveis causas desta diminuição, a partir do que sugere a literatura internacional: i) perda de espaço para outros ramos da área; ii) ausência de aprofundamento nos estudos; iii) pouca criatividade dos pesquisadores; iv) dificuldade para acessar dados; v) orientação excessiva para descrever práticas gerenciais (LUNKES, et al., 2011).

Entre os temas mais explorados nas pesquisas de contabilidade gerencial estão: sistemas de controle gerencial, contabilidade de custos, gerenciamento de custos, informações e sistemas de contabilidade gerencial (ARAUJO; SILVA, 2010). No entanto, o crescimento quantitativo na produção em contabilidade gerencial, quando ocorre, a exemplo do que se constatou período de 1998 a 2003 por Cardoso, Pereira e Guerreiro (2004), não é necessariamente acompanhado por crescimento qualitativo.

A análise crítico-epistemológica da produção científica em Contabilidade no Brasil, feita por Theóphilo e Iudícibus (2005) a partir de artigos do Congresso EnANPAD, e teses e dissertações de programas de mestrado e doutorado acadêmicos em contabilidade, publicados no período de 1994 a 2003 (CAPES) mostrou a classificação epistemológica destes manuscritos, considerando que a geração do conhecimento científico ocorre a partir de quatro níveis: epistemológico, teórico, metodológico e técnico. Sob a dimensão técnica, das 238 pesquisas analisadas, 103 são Estudos Teóricos, e outros 135 Estudos Teórico-Empíricos. Sob a dimensão metodológica, as pesquisas são: empirista (10), positivista (107), sistêmica/estruturalista (28), fenomenológica hermenêutica (6), outra (21), prejudicado (66).

Dentro da dimensão teórica, a categoria postura teórica compreende a postura positiva que pretende explicar o que é, e postura normativa que busca prescrever o que deve ser. Theóphilo e Iudícibus (2005) destacam uma peculiaridade na amostra analisada, na qual se verifica, de um lado, uma postura normativa e crescimento em profundidade; e, de outro, postura positiva e crescimento em superfície. "Assim, a grande maioria dos estudos da linha de investigação 'o que deve ser' desenvolve propostas com propósitos inovadores; por sua vez, a quase totalidade dos estudos baseados na linha 'o que é' realiza investigações amparadas em teorias, doutrinas ou conceitos já existentes” (THEÓPHILO; IUDÍCIBUS, 2005, p. 164, grifos dos autores).

Os autores concluíram que há uma mudança de paradigma: pesquisas teóricas de postura normativa com investigação em profundidade estão dando espaço para pesquisas positivas de investigações em superfície, com base em teorias existentes, e aceitas pela comunidade científica. Adicionalmente, a pesquisa ainda revelou pouca utilização das diversas alternativas metodológicas disponíveis. Muito embora o estudo destes autores não esteja pautado exclusivamente em publicações de contabilidade gerencial, ele sinaliza para o posicionamento da pesquisa contábil no Brasil, dentro da abordagem mainstream, em termos de normativismo e positivismo, como mostra também a pesquisa de Martins (2005). Além disso, embora os autores apresentem uma classificação interessante, ela não permite 
identificar claramente a presença de estudos interpretativos e críticos durante os dez anos analisados, tal fato poderia consistir em uma pista da ausência destes?

Nascimento, Junqueira e Martins (2010) analisaram estritamente a contabilidade gerencial, a partir da plataforma teórica, das estratégias de pesquisas, das abordagens teóricas e das perspectivas paradigmáticas adotadas nas pesquisas. A análise sobre teorias, metodologias e paradigmas buscou evidenciar as características epistemológicas da produção acadêmica em contabilidade gerencial. A análise sobre as teorias mostrou que $83 \%$ dos trabalhos analisados estão fundamentados apenas em conceitos contábeis ou legislação; enquanto apenas $17 \%$ dos trabalhos usam teorias provenientes da economia, sociologia ou psicologia. Concernente aos paradigmas de pesquisa, a análise evidenciou que $97 \%$ da literatura brasileira seguem o paradigma funcionalista, e 3\% adotam os paradigmas interpretativos, críticos ou pós-estruturalistas.

Martins e Zanchet (2012) também concentraram sua análise na contabilidade gerencial em busca da complexidade epistemológica em estudos na área. Os autores mostraram que as pesquisas estão muito afastadas da matriz das complexidades, dado que os pesquisadores evidenciaram espírito científico, incapaz de se repensar, e estão firmados na crença de que o conhecimento científico é o reflexo do real. Os autores complementam que as pesquisas possuem abordagem positivista, utilizam métodos e técnicas estatísticas e não possuem profundidade na análise dos resultados obtidos.

O cenário representado pelos estudos anteriormente citados revela um quadro de baixo interesse e envolvimento com abordagens alternativas, mais especificamente interpretativas e críticas, em contabilidade gerencial no Brasil. Ao revisitar autores internacionais vinculados a essas perspectivas, e confrontarmos com o cenário nacional, é possível perceber a existência de grande potencial para enriquecer o debate nacional sobre a construção do conhecimento em contabilidade gerencial, e descortinar novas possibilidades para pesquisa além daquelas usualmente utilizadas.

Há espaço para que, no Brasil, possamos ampliar o entendimento de que a contabilidade está entrelaçada a processos sociais, culturais e políticos, e esta identidade é acompanhada por um imperativo. Com isso, pesquisadores em contabilidade gerencial, no Brasil, podem voltar sua atenção à forma como, de maneira específica, o potencial construtivo "da contabilidade é trabalhado pelos designers e usuários de sistemas de contabilidade" (Ahrens, 2008, p. 842) ou, até mesmo, "considerar as implicações das práticas contábeis nas relações de poder e na (re)produção das diferenças e das desigualdades sociais, econômicas e culturais" (WILLMOTT, 2008, p. 921).

\section{Reflexões e Considerações Finais}

O objetivo do presente artigo foi revisitar as diferentes possibilidades epistemológicas em contabilidade, de forma a apontar como contribuições de abordagens interpretativas e críticas podem enriquecer a construção do conhecimento em contabilidade gerencial no contexto brasileiro.

Desenvolvemos, ao longo texto, uma argumentação calcada no entendimento de que repensar a produção em contabilidade gerencial no Brasil se torna importante, não apenas para identificar em que estágio a pesquisa se encontra, mas, principalmente, para refletir sobre 
como o preenchimento de lacunas existentes pode enriquecer o que já se conhece, ou auxilia a reconhecer aquilo que ainda não está tão claro.

Se pensarmos nas perspectivas possíveis para investigações em contabilidade gerencial no Brasil - mainstream, interpretativa, crítica - podemos indubitavelmente afirmar que pesquisas interpretativas e críticas ocupam um espaço reduzido, e a despeito de pouco ter sido desenvolvido até o momento a partir dessas abordagens teóricas, o cenário revela uma importante lacuna a ser preenchida por pesquisadores da área.

Pesquisas interpretativas e críticas exigem, do pesquisador, metodologias e habilidades diferentes daquelas que normalmente são utilizadas em pesquisas com uma configuração positivista. Estas perspectivas têm oportunizado compreender a contabilidade gerencial para além dos números, e permitido entender como questões como poder, estrutura, agência e tecnologias se produzem e reproduzem no dia-a-dia das organizações.

Em termos de reflexões finais, considerarmos oportuna a arguição de Vaivio (2008) para responder a questão dolorosa - quase existencial, de pesquisadores de contabilidade gerencial: pesquisa qualitativa em contabilidade gerencial realmente importa?. O autor afirma que sim, a partir de três chaves. Primeiro, as pesquisas qualitativas ampliam a visão estreita e funcionalista do fenômeno contabilidade gerencial, tal qual apresentada em livros didáticos de contabilidade.

Sob essa visão didática há um conjunto de ferramentas de contabilidade gerencial formalizado e sistemático para ser aplicado no dia a dia das empresas que possuem um gerente responsável pela tomada de decisão, que se desenrolará a partir de objetivos cuidadosamente traçados. Adicionalmente, toda ação será acompanhada por rotinas de controle. No entanto, na vida real, as decisões são complexas e raramente lineares e racionais, envolvem diversos atores e jogos de poder, aspectos que desafiam a aplicação desta caixa de ferramentas apresentada como ideal. Dessa forma, um entendimento mais profundo de contabilidade gerencial requer estudos qualitativos interpretativos e críticos (VAIVIO, 2008).

Em segundo lugar, as pesquisas qualitativas oferecem proteção "contra um imperialismo científico que reduz contabilidade gerencial a uma questão de mera opção econômica". Neste sentido, Vaivio (2008) discorre que o ponto de vista econômico, ao assumir os pressupostos da economia neoclássica, considera que a contabilidade gerencial pode ter seus termos modelados, e a firma é uma grande caixa preta, na qual os inputs maximizam os outputs. A pesquisa qualitativa rejeita essa caixa negra e vai além da teoria da firma para entender o fenômeno, e tem mostrado como os processos políticos envolvem a contabilidade gerencial e governam a vida econômica da empresa.

Em terceiro, as pesquisas qualitativas oferecem análise crítica das prescrições normativas para melhorar a contabilidade gerencial, sob uma perspectiva de consultoria. Sob esse ponto de vista tem se massificado a venda de produtos gerenciais, propagado a necessidade de melhoria, de mudança e de novas ferramentas de contabilidade gerencial. Há uma tendência de propagar modismos. A pesquisa qualitativa posiciona-se quanto às prescrições, e destaca o ambiente singular de aplicação de cada ferramenta gerencial (VAIVIO, 2008).

Sob o entendimento de que haverá profundidade na construção do fenômeno contabilidade gerencial a partir da utilização de outras lentes para investigação, o que não significa simplesmente mesclar ontologias, epistemologias e metodologias de diferentes paradigmas, consideramos que a discussão sobre a construção do conhecimento torna-se relevante para a contabilidade gerencial no Brasil. 
Ao considerar algumas pesquisas realizadas na área, concordamos que pesquisadores em contabilidade gerencial, no contexto brasileiro, parecem ver o mundo de uma forma muito objetiva, ao menos sob a análise apresentada por Martins e Zanchet (2012). Contudo, como explicitaram Ryan et al. (2002) e Smith (2011), pesquisas alternativas em contabilidade gerencial requerem uma visão mais subjetiva e crítica da realidade; necessitam de aprofundamento de análise, direcionada pela descoberta de significados e crenças subjacentes às ações; requerem melhoria do status quo, mediante desenvolvimento prático e público do conhecimento; e podem evidenciar facetas ainda não exploradas, no que tange a contabilidade gerencial.

Como exposto ao longo do texto, pesquisas mainstream são preferidas nos Estados Unidos, e igualmente no contexto brasileiro essa preferência mostra-se verdadeira. Tal fato evidencia a oportunidade para que pesquisas sob outras abordagens sejam mais exploradas no Brasil. Para tal, conforme sugeriram autores citados ao longo do texto, é necessário: (i) aprimorar a formação dos pesquisadores em contabilidade, de forma a permitir o reconhecimento das possibilidades e limitações do mainstream e, ao mesmo, o envolvimento com abordagens interpretativas e críticas; (ii) abrir espaço nos programas e laboratórios de pesquisa para que ocorra o envolvimento com abordagens interpretativas e críticas, mesmo que em triangulação teórico-metodológica com o mainstream; (iii) fomentar, nos periódicos nacionais em contabilidade, o engajamento com abordagens outras, de forma a encorpar a construção do conhecimento desta complexa realidade, para a qual está envolta a ciência contábil gerencial brasileira.

Nesse sentido, alinhamos nossa argumentação aos autores europeus e reconhecemos que as abordagens dominantes e as alternativas em contabilidade gerencial oferecem contribuições para o desenvolvimento da ciência contábil. Dada a complexidade dos fenômenos contábeis e organizacionais, determinados problemas serão insuficientemente explorados, se forem tratados sob um único ponto de vista. Neste caso, outras abordagens serão importantes e mais aptas para determinados graus de complexidade e interpretação da realidade. Por isso, a ausência de abertura para pesquisas de outras naturezas pode dificultar o amadurecimento contábil gerencial no contexto brasileiro.

Esta argumentação é consonante com o reconhecimento de que não há uma única verdade dentro da ciência contábil, e outras perspectivas podem enriquecer e aproximar o entendimento daquilo que já é conhecido. Como bem assinala Feyerabend (1977), o avanço não está em sintonia com metodologias únicas, portanto, ficar preso a metodologias únicas é engessar o conhecimento científico e o progresso. Sob um olhar que recomenda esforço investigativo criterioso, reconhecemos que adotar uma abordagem pluralista pode oferecer resultados distintos e, de fato, gerar conhecimentos de outra ordem.

\section{Referências}

AHRENS, T. Overcoming the subjective-objective divide in interpretive management accounting research. Accounting, Organizations and Society, n. 33, p. 292-297, 2008.

ARAÚJO, E. A. T.; SILVA, W. A. C. Pesquisa científica em contabilidade gerencial nos Enanpads de 2003 a 2008. Revista Universo Contábil, v. 6, n. 3, p. 29-44, 2010. 
BAKER, C. R.; BETTNER, M.S. Interpretative and critical research in accounting a commentary on its absence from mainstream accounting research. Critical Perspectives on Accounting, n. 8, p. 193-310, 1997.

BAXTER, J.; CHUA, W. F. Alternative management accounting research - whence and whither. Accounting. Organizations and Society, v. 28, p. 97-126, 2003.

BURRELL, G.; MORGAN, G. Sociological Paradigms and Organisational Analysis. London: Heinemann, 1979.

CARDOSO, R. L.; OYADOMARI, J. C.; MENDONÇA NETO, O. R. Influências da Positive Accounting nos Programas de Mestrado em Contabilidade: uma análise bibliométrica da produção acadêmica de 2002 a 2005. BBR. Brazilian Business Review, v. 4, p. 158-170, 2007.

CARDOSO, R. L.; PEREIRA. C. A.; GUERREIRO, R. A produção acadêmica em custos no âmbito do ENANPAD: uma análise de 1998 a 2003. In: $28^{\circ}$ ENANPAD, 2004, Curitiba, 2004, Curitiba, Anais... - CD-ROM, Curitiba: 2004.

CHUA, W. F. Radical developments in accounting thought. Accounting Review, v. 61, n. 4, p. 601-632, 1986.

CRUZ, A. P. C. et al. Uma Análise do Desenvolvimento do Campo de Pesquisa em Contabilidade Gerencial sob a Perspectiva Colaborativa. Contabilidade Vista \& Revista, v. 21, n. 2, p. 95-120, 2010.

FEYERABEND, P. Contra o método. Rio de Janeiro: F.Alves, 1977.

FREZATTI, F., NASCIMENTO, A. R.; JUNQUEIRA, E. Desenvolvimento da pesquisa em contabilidade gerencial: as restrições da abordagem monoparadigmática de Zimmerman.

Revista Contabilidade e Finanças, v. 20, n. 6, 2009.

HOPPER, T.; POWEL, A. Making sense of research into organizational and social aspects of management accounting: a review of its underlying assumptions. Journal of Management Studies, v. 22, n. 5, p. 429-465, 1985.

HOPWOOD, A. G. The archaeology of accounting systems. Accounting, Organizations and Society, v. 13, n. 3, p. 207-234, 1987.

HOPWOOD, A. G. If only there were simple solutions, but there aren't: some refl ections on Zimmerman's critique of empirical management accounting research. The European

Accounting Research, v. 11, n. 4, p. 777-785, 2002.

HOQUE, Z.; COVALESKI, M. A.; GOONERATNE, T. N. A response to "theoretical triangulation and pluralism in accounting research: a critical realist critique". Accounting, Auditing \& Accountability Journal, v. 28, n. 7, p. 1151-1159, 2015. 
ITTNER, C. D.; LARCKER, D. F. Assessing empirical research in managerial accounting: a value-based management perspective. Journal of Accounting and Economics, v. 32, p. 349$410,2001$.

ITTNER, C. D.; LARCKER, D. F. Empirical managerial accounting research: are we just describing management consulting practice? The European Accounting Research, v. 11, n. 4, p. 787-794, 2002.

IUDÍCIBUS, S., et al. Uma Reflexão sobre a contabilidade: caminhando por trilhas da "teoria tradicional e teoria crítica". BASE, v. 8, n. 4, p. 274-285, 2011.

JENSEN, M. C.; MECKLING, W. H. Theory of the firm: managerial behavior, agency costs and ownership structure. Journal of Financial Economic, v. 3, 1976.

LAUGHLIN, R. Methodological themes Empirical research in accounting: alternative approaches and a case for "middle-range" thinking. Accounting, Auditing \& Accountability Journal, v. 8, n. 1, p. 63-87, 1995.

LEE, B.; HUMPHREY, C. More than a numbers game: qualitative research in accounting. Management Decision, v. 44, n. 2, p. 180-197, 2006.

LUFT, J.; SHIELDS, M. D. Zimmerman's contentious conjectures: describing the present and prescribing the future of empirical management accounting research. The European Accounting Review, v. 11, n. 4, p. 795-805, 2002.

LUFT, J.; SHIELDS, M. D.. Mapping Management Accounting. In: CHAPMAN, C. S.; HOPWOOD, A. G.; SHIELDS, M. D. Handbook of Management Accounting Research. Oxford: Elsevier, p. 27-98, 2007.

LUKKA, K. The roles and effects of paradigms in accounting research. Management Accounting Research, v. 21, p. 110-115, 2010.

LUNKES, R. J. et al. Análise da produção cientifica e formação de doutores em contabilidade gerencial: um estudo no cenário brasileiro. Advances in Scientific and Applied Accounting, v. 4, n. 3, p. 361-378, 2011.

MARTINS, E. Normativismo e/ou Positivismo em Contabilidade: Qual o Futuro? Revista de Contabilidade e Finanças, v. 39, n. 3, 2005.

MARTINS, G. A. M.; ZANCHET, A. Sobre a complexidade dos achados de pesquisas contábeis. In: COLOQUIO INTERNACIONAL DE EPISTEMOLOGIA E ADMINISTRAÇÃO, 2, 2012. Anais... Colóquio Internacional de Epistemologia Administração, Florianópolis, Brasil, 2012. 
MENSAH, Y. M.; HWANG, N. C. R.; WU, D. Does managerial accounting research contribute to related disciplines? An examination using citation analysis. Journal of Management Accounting Research, v. 16, n. 1, p. 163-181, 2004.

MIRANDA, C. S.; RICCIO, E. L.; MIRANDA, R. A. M. O ensino da contabilidade gerencial no Brasil: uma avaliação de grades curriculares e literatura didática. Revista Contabilidade e Controladoria, v. 5, n. 2, p. 25-42, 2013.

MODELL, S. Bridging the paradigm divide in management accounting research: The role of mixed methods approaches. Management Accounting Research, v. 21, p. 124-129, 2010.

MODELL, S. In defence of triangulation: a critical realist approach to mixed methods research in management accounting. Management Accounting Research, v. 20, n. 3, p. 208$221,2009$.

MODELL, S. Theoretical triangulation and pluralism in accounting research: a critical realist critique. Accounting, Auditing \& Accountability Journal, v. 28, n. 7, p.1138-1150, 2015.

NASCIMENTO, A. R., JUNQUEIRA, E.; MARTINS, G. A. A pesquisa acadêmica em contabilidade gerencial no Brasil: análise e reflexões sobre teorias, metodologias e paradigmas. RAC, v. 14, n. 6, p. 1113-1133, 2010.

NEU, D., COOPER, D. J.; EVERETT, J. Critical accounting interventions. Critical Perspectives on Accounting, v. 12, p. 735-762, 2001.

PADOAN, F. A. C. A interdisciplinaridade no ensino da contabilidade gerencial em instituições públicas de ensino superior do Estado do Paraná. 2007. 96 f. Dissertação (Mestrado em Contabilidade), Universidade Federal do Paraná, Curitiba, 2007.

PRASAD, P. Postcolonialism: Unpacking and Resisting Imperialism. In: Prasad, Pushkala. Crafting Qualitative Research: Working in the postpositivist traditions. New York: M.E. Sharpe, 2005, p. 262-281.

REIS, L. G.; PEREIRA, C. A. Uma análise das contribuições das teorias organizacionais para o estudo da contabilidade gerencial. In: CONGRESSO USP DE CONTROLADORIA E CONTABILIDADE, 2007. Anais... Congresso USP controladoria e contabilidade, São Paulo, SP, Brasil, 2007.

ROSLENDER, R.; DILLARD, J. Reflections on the interdisciplinary perspectives on accounting project. Critical Perspectives on Accounting, v. 14, p. 325-351, 2003.

RYAN, B.; SCAPENS, R. W.; THEOBOLD, M. Research Method and Methodology in Finance and Accounting. London: Wouth Wester: Cengage Learning, 2002.

SCAPENS, R. W. Seeking the relevance of interpretive research: A contribution to the polyphonic debate. Critical Perspectives on Accounting, v. 19, p. 915-919, 2008. 
SMITH, M. Research methods in accounting. London: SAGE Publications, 2011.

SOUZA, F. R.; BORGERT, A.; RICHARTZ, F. Análise do conteúdo das ementas das disciplinas relacionadas à área gerencial. 2012. RIGC, v. 10, n. 20, 2012

THEOPHILO, C. R.; IUDICIBUS, S. Uma Análise Crítico-Epistemológica da Produção Científica em Contabilidade no Brasil. UnB Contábil, v. 8, n. 2, 2005.

THOMKINS, C.; GROVES, R. The everyday accountant and researching his reality. Accounting, Organizations and Society, v. 8, n. 4, p. 361-374, 1983.

VAIVIO, J. Qualitative management accounting research: rationale, pitfalls and potential. Qualitative Research in Accounting \& Management, v. 5, n. 1, p. 64 - 68, 2008.

WILLMOTT, H. Listening, Interpreting, Commending: a commentary on the future of interpretive accounting research. Critical Perspectives on Accounting, v. 19, p. 920-925, 2008.

ZIMMERMMAN, J. L. Conjectures regarding empirical managerial accounting research. Journal of Accounting and Economics, v. 32, p. 411-427, 2001. 